\title{
EDITORIAL
}

\section{The brain, ageing, and dementia}

In some diseases of the nervous system there is a satisfyingly complete chain between clinical disorder, distribution and nature of the lesions, underlying biochemical causes and consequences, and thus a rational treatment. There are also too many others in which understanding of these steps is minimal, even as far as uncertainty about where studies of aetiology and pathogenesis should begin.

Such difficulties are well shown by the associations suggested between the effects of ageing on the brain and certain forms of dementia. On the one hand are the problems, verging on the philosophical, of defining 'age', both as a general biological phenomenon (Comfort, 1964), and as the terminal phase in the development of a particular organ; and on the other is the need in clinical practice among elderly patients to disentangle intrinsic aspects of senescence from probable extraneous factors, such as arteriosclerosis. Both may be 'worse confounded' should an attempt be made to correlate the dementia with the distribution of the various types of lesions found in the brain. In the circumstances, as the links between ageing and dementia are not clear, perhaps the best that can be done is to establish the questions required to evaluate what is common to the brain in these two conditions. Any such analysis is biased by the inquirer's own frame of reference, so the reader should beware of the underlying trends here of concentration on organic lesions, and the morbid anatomist's reluctant awareness of significant lesions at a biochemical or functional level that cannot be demonstrated by the most sophisticated histological technique. It seems profitable to ask about the nature of 'intrinsic' ageing processes in the brain; the relative importance of dementia and other psychiatric disorders in later life and how they can be assessed; what are the known structural or biochemical changes in the brains of affected patients; whether they can be correlated in any way with the intellectual disorders; what reasonable grounds exist for predicting the nature or sites of as yet unidentified lesions, and thus where and how to look for them; and, lastly, if lesions found in dementia resemble those found in normal ageing, has their similarity any significance for attempts to prolong human life?

The biological importance of ageing has been a subject of seemingly infinite appeal, both to philosophical and pragmatic biologists, and they have yet to agree about much of what they have studied. Medawar (1952) and Comfort (1964) may be taken as guides to modern ideas about aspects of ageing through the animal kingdom. The gulfs between their theoretical analyses, hypotheses of generalized mechanisms of senescence (a concept that itself begs many questions, for why should all tissues be expected to age in the same way or by the same mechanism?), and pathological findings in cells and tissues have been discussed in general by Rowlatt and Franks (1973), and in the brain in particular by Dayan (1972). If the strength of a scientific theory lies in its generality, simplicity, and clarity, then it may safely be concluded that no universal mechanism of senescence has yet been proven (Goldstein, 1971) - for example, errors in protein synthesis, immunological crises, auto-oxidation, and abnormal cross-linking of proteins have all been demonstrated in restricted circumstances, and slow viruses have been invoked for no very good reason, but none has been shown to be applicable to the brain. Valuable though senescence may be to the impartial and remote guardian of evolution, its physical meaning at the level of organism or cell remains in doubt.

More is known about the morphological lesions found in elderly man. Pathological changes in the brain in normal aged people have been discussed by Gellerstedt (1933) and Tomlinson et al. (1968), and reviewed by Dayan (1973). There is general agreement about overall loss of weight of the brain, though not about its cause, and about histological lesions that may be divided into the important and the trivial. The former include intraneuronal neurofibrillary tangles and argyrophilic (senile) plaques in the cortical neuropil, and perhaps amyloid deposits around superficial cortical and pial blood 
vessels. The latter are a treasure of eponymous irrelevancies. Recent advances have moved the lightmicroscopists' delight of plaques and tangles to the forefront of molecular biology, as they have been shown probably to represent fundamental changes in the protein subunits of microtubules. The latter are responsible for the intracellular transport of essential metabolites on which the continued existence or functioning of axons, dendrites and synapses appears to depend in so dispersed a cell as the neuron. Tangles represent intraneuronal accumulations of abnormal, twisted tubules, and plaques are foci of degeneration of nerve cell processes, in which amyloid sometimes appears (Terry, 1971; Terry and Wiśniewski, 1972). Whether neurons are lost during normal senescence is not known, although evidence is hardening against this idea (Blinkov and Glezer, 1968; Dayan, 1971; Konigsmark and Murphy, 1972; 'neuromythology' according to Tomasch, 1971).

The intellectual and psychiatric consequences of growing old, and the nosology of the mental disorders of that period of life have been of recent interest (Post, 1965; Bromley, 1966; Mayer-Gross, et al., 1969; Davies, 1972). Data from detailed clinical surveys in Newcastle, which are representative of British experience and probably are reasonably so of the rest of western Europe and of North America, have shown an overall prevalence of $10 \%$ of all forms of dementia in persons more than 65 years old (Kay et al., 1964; Bergmann 1969; Kay et al., 1970).

About half of the cases are due to various consequences of arteriosclerosis and most of the remainder to 'senile dementia'- that is, a specific disease with a recognizable pattern of pathological lesions. The morphological changes underlying senile dementia have been defined with some precision in large series collected from hospitals and from people living in the community by Sjögren et al. (1952), Corsellis (1962), Sourander and Sjögren (1970), and Tomlinson et al. (1970). It is now held that, contrary to older opinions-for example, Rothschild (1937)-there is no difference between 'senile dementia' of this specific type and Alzheimer's 'presenile dementia', other than the academic division in time between 'senility' and 'pre-senility'. The more important changes found in senile dementia comprise shrinkage of the brain, especially of the frontal and temporal lobes; loss of neurons there, as well as from other parts of the cerebral cortex and amygdaloid nuclei; the appearance of senile or agyrophilic plaques in the neuropil and of neurofibrillary tangles in nerve cells in the cortex and amygdaloid nuclei, and sometimes of amyloid deposits around small blood vessels in the pia and superficial cortex. The biochemical basis of these changes is unknown. The pathological substrate of arteriosclerotic dementia has been less easy to define, as might be expected from the pleomorphic nature of the process. There is a multiplicity of large and small lesions, focal infarcts, and haemorrhages, distal atheromatous occlusion of large arteries, local thromboses, microemboli, and systemic hypotension, all of varying importance (Dayan, 1973; Isaacs, 1973). Suffice it to note that the total volume of brain destroyed seems to be of as much importance as the location of the lesions (Tomlinson et al., 1970), except in the instance of certain specific disorders due to focal destruction at critical sites-see, for example, Brierley's (1966) analysis of the pathology of memory.

The quantitative significance of the morphological lesions of senile dementia is not as clear as might be desired, because all the changes may be found to some extent in apparently healthy old people of similar age. Some correlation exists between the intensity of certain pathological lesions (especially plaques) and the occurrence and degree of mental disorder, but the agreement is imperfect (Tomlinson et al., 1968, 1970). There is an unfortunate philosophical belief in neuropathology that all lesions seen must be used to explain some clinical disorder. The brain is not so simple, and it is necessary to beware of reviving sophisticated versions of the long-demolished engram by making too much of chance clinicopathological associations. The potential value of studies in animals has yet to be realized. A comparative psychology of ageing has hardly been attempted, and comparative neuropathology has not been very fruitful, as the more striking neuronal changes in man either have not been seen at all in animals, or have occurred only rarely (Dayan, 1971; Wiśniewski et al., 1973).

What pointers are there from present knowledge for future research? At the clinical level, better criteria are needed for the differential diagnosis of dementia and more precise methods for investigation of the mechanisms of disordered intellect (Pearce, 1973). Our poverty of diagnostic skills is shown by the recent rise and fall in the popularity of low pressure hydrocephalus as the cause of de- 
mentia and shunt operations for its cure. How much more understanding about pathogenetic mechanisms might be gained from improved psychological and psychometric tests? As senile dementia involves progressive degeneration of neurons, could biochemical tests be of more diagnostic help? Could specific enzymes or structural proteins leak from the brain as nerve cells degenerate and accumulate sufficiently in the cerebrospinal fluid (CSF) sink to become detectable in lumbar puncture specimens, if not in serum? The diffuse nature of the lesions in the cerebral cortex makes it highly unlikely that any single neurotransmitter would be affected as cell processes degenerate, so there is no reason to anticipate as unique a biochemical marker in senile dementia as the disorders of cerebral dopamine metabolism in Parkinsonism. However, it might still be worth looking at the turnover and fate of putative cortical neurotransmitters in terms of their CSF levels.

Where might conventional neuropathology help? Perhaps the most immediate need, and by far the most difficult to fulfil, is to know accurately the volume of grey matter in normal and in demented patients, and then to estimate neuronal loss in various areas and to assess its pathogenetic significance. Colon's (1973) quantitative demonstration of loss of cortical neurons in two cases of 'presenile' dementia is exciting but requires the support of much larger numbers. The classical neuropathologist could help by studying more carefully the distribution of plaques and tangles in other areas than the cerebral cortex, for patients with senile dementia may have signs of damage elsewhere in the brain-for example, abnormal movements, perhaps arising from the basal ganglia, features of hypothalamic dysfunction, etc. At a cellular level, there is a pressing need to know that happens to neurons involved by the formation of plaques and tangles. To what extent are nerve cells lost and from where, or is there a physiologically more important loss of dendritic and axonal ramifications or synapses, perhaps because of failure of intracellular transport mechanisms? It is from biochemistry, however, that advances will probably come soonest. Already (Bowen et al., 1973) the estimation of cell-specific proteins is a promising alternative to the tedious and inaccurate job of counting cells in sections. It should not be long before direct approaches can be made to the metabolic activity of affected neurons and to the nature and effects of the neurofibrillary tangle and senile plaque, aided by quantitative cytochemistry and electrophysiology. Without such knowledge, a rational approach to treatment cannot be attempted, neither preventive nor with the less ambitious aim of relieving the effects of dysfunction.

The fundamental questions still remain concerning the aetiology of senile dementia and its relationship to senescence in general. We are ignorant of both. The former has run the gamut of every theory current in medicine and has been satisfied by none; it has still not been possible even to decide the relative importance of exogenous and endogenous genetic factors (Hunter et al., 1973). The brain has even been proposed as the 'clock' which determines the chronology of the entire body-indeed, a speculation in search of any available support. Anyone taking up the unfashionable discipline of psychiatric neuropathology seems assured of a busy and profitable old age.

A. D. DAYAN

\section{REFERENCES}

Bergmann, K. (1969). The epidemiology of senile dementia. British Journal of Hospital Medicine, 2, 727-732.

Blinkov, S. M., and Glezer, I. I. (1968). The Human Brain in Figures and Tables. Plenum Press: New York.

Bowen, D. M., Smith, C. B., and Davison, A. N. (1973). Molecular changes of senile dementia. Brain, 96, 849-856.

Brierley, J. B. (1966). The neuropathology of amnesic states. In Amnesia, pp. 150-180. Edited by C. W. M. Whitty and O. L. Zangwill. Butterworths: London.

Bromley, D. B. (1966). The Psychology of Human Ageing. Penguin: Harmondsworth.

Colon, E. J. (1973). The cerebral cortex in presenile dementia: a quantitative study. Acta Neuropathologica (Berlin), 23, 281-290.
Comfort, A. (1964). Ageing. The Biology of Senescence. Routledge: London.

Corsellis, J. A. N. (1962). Mental Illness and the Ageing Brain. Maudsley Monograph No. 9. Oxford University Press: London.

Davies, A. D. M. (1972). The effects of age, sex and occupation on selected psychological and physical variables. In Ageing of the Central Nervous System, pp. 101-122. Edited by H. M. van Praag and A. F. Kalveboer. Bohn: Haarlem.

Dayan, A. D. (1971). Comparative neuropathology of ageing. Brain, 94, 31-42.

Dayan, A. D. (1972). The brain and theories of ageing. In Ageing of the Central Nervous System, pp. 58-75. Edited by H. M. van Praag and A. F. Kalveboer. Bohn: Haarlem. 
Dayan, A. D. (1973). Neuropathology of aging. In Textbook of Geriatric Medicine and Gerontology, pp. 161-191. Edited by J. C. Brocklehurst. Churchill Livingstone: Edinburgh.

Gellerstedt, N. (1933). Zur Kenntnis der Hirnveränderungen bei der normalen Altersinvolution. Uppsala Läkareförenings Förhandlingar, 38, 193-408.

Goldstein, S. (1971). The biology of aging. New England Journal of Medicine, 285, 1120-1129.

Hunter, R., Dayan, A. D., and Wilson, J. (1972). Alzheimer's disease in one monozygotic twin. Journal of Neurology, Neurosurgery, and Psychiatry, 35, 707-710.

Isaacs, B. (1973). Stroke. In Texibook of Geriatric Medicine and Gerontology, pp. 210-230. Edited by J. C. Brocklehurst. Churchill Livingstone: Edinburgh.

Kay, D. W. K., Beamish, P., and Roth, M. (1964). Old age mental disorders in Newcastle upon Tyne. British Journal of Psychiatry, 110, 146-158.

Kay, D. W. K., Bergmann, K., Foster, E. M., McKechnie, A. A., and Roth, M. (1970). Mental illness and hospital usage in the elderly: a random sample followed up. Comprehensive Psychiatry, 11, 26-35.

Konigsmark, B. W., and Murphy, E. A. (1972). Volume of the ventral cochlear nucleus in man: its relationship to neuronal population and age. (Abstract.) Journal of Neuropathology and Experimental Neurology, 31, 200.

Mayer-Gross, W., Slater, E., and Roth, M. (1969). Clinical Psychiatry, 3rd edn. Baillière: London.

Medawar, P. B. (1952). An Unsolved Problem of Biology. Lewis: London.

Pearce, J. (1973). Clinical Aspects of Dementia. Baillière: London.

Post, F. (1965). The Clinical Psychiatry of Later Life. Pergamon Press: Oxford.

Rothschild, D. (1937). Pathologic changes in senile psychoses and their psychobiologic significance. American Journal of Psychiatry, 93, 757-788.

Rowlatt, C., and Franks, L. M. (1973). Aging in tissues and cells. In Textbook of Geriatric Medicine and Gerontology, pp. 1-16. Edited by J. C. Brocklehurst. Churchill Livingstone: Edinburgh.

Sjögren, T., Sjögren, H., and Lindgren, A. G. H. (1952). Morbus Alzheimer and Morbus Pick. A genetic, clinical and patho-anatomical study. Acta Psychiatrica et Neurologica Scandinavica, Suppl. 82.

Sourander, P., and Sjögren, H. (1970). The concept of Alzheimer's disease and its clinical implications. In Alzheimer's Disease and Related Conditions, pp. 11-36. Edited by G. E. W. Wolstenholme and M. O'Connor. Churchill: London.

Terry, R. D. (1971). Neuronal fibrous protein in human pathology. Journal of Neuropathology and Experimental Neurology, 30, 8-19.

Terry, R. D., and Wiśniewski, H. M. (1972). Ultrastructure of senile dementia and of experimental analogs. In Aging and the Brain, pp. 89-116. Edited by C. M. Gaitz. Plenum Press: New York.

Tomasch, J. (1971). Comments on "neuromythology". Nature, 233, 60.

Tomlinson, B. E., Blessed, G., and Roth, M. (1968). Observations on the brains of non-demented old people. Journal of the Neurological Sciences, 7, 331-356.

Tomlinson, B. E., Blessed, G., and Roth, M. (1970). Observations on the brains of demented old people. Journal of the Neurological Sciences, 11, 205-242.

Wiśniewski, H. M., Ghetti, B., and Terry, R. D. (1973). Neuritic (senile) plaques and filamentous changes in aged rhesus monkeys. Journal of Neuroparhology and Experimental Neurology, 32, 566-584. 